Federal Reserve Bank of Minneapolis

Quarterly Review

Fall 1984

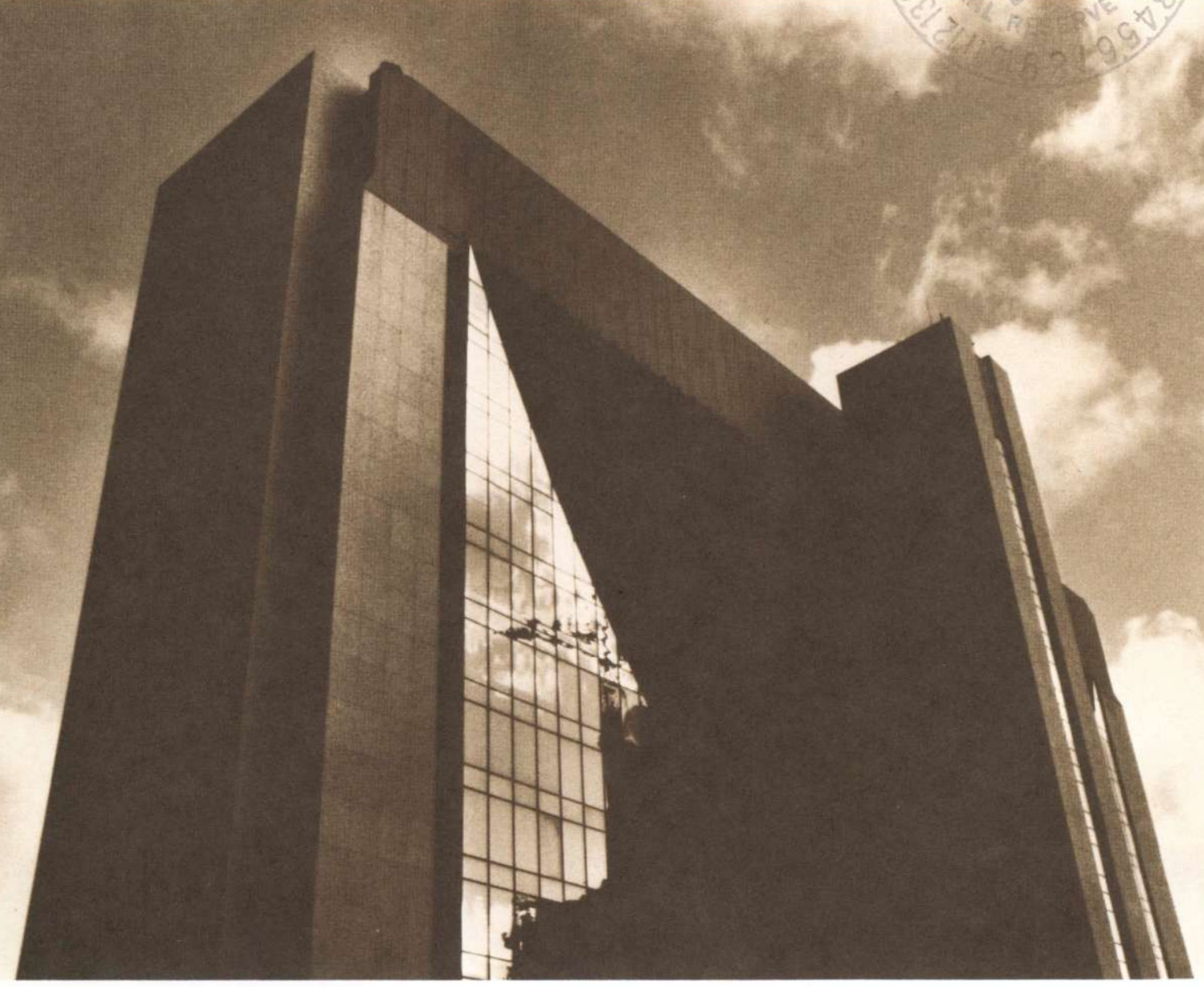

Above-Average National Growth in 1985 and 1986

Robert B. Litterman (p. 3)

More Growth Ahead

for Ninth District States

Hossain Amirizadeh Richard M. Todd (p. 8)

Improving Economic Forecasting With Bayesian Vector Autoregression

Forecasting and Policy Analysis With Bayesian Vector Autoregression Models Robert B. Litterman (p. 30) 
Federal Reserve Bank of Minneapolis

Quarterly Review vol. 8, No.4 ISSN 0271-5287

This publication primarily presents economic research aimed at improving policymaking by the Federal Reserve System and other governmental authorities.

Produced in the Research Department. Edited by Preston J. Miller, Kathleen S. Rolfe, and Inga Velde.

Graphic design by Phil Swenson and typesetting by Barbara Cahlander and Terri Desormey, Graphic Services Department.

Address requests for additional copies to the Research Department,

Federal Reserve Bank, Minneapolis, Minnesota 55480.

Articles may be reprinted if the source is credited and the Research Department is provided with copies of reprints.

The views expressed herein are those of the authors and not necessarily those of the Federal Reserve Bank of Minneapolis or the Federal Reserve System. 


\section{Above-Average National Growth in 1985 and 1986}

Robert B. Litterman

\section{Senior Economist}

Research Department

Federal Reserve Bank of Minneapolis

The slowdown in U.S. economic growth in the second half of 1984 is most likely only a short pause in the current expansion. In fact, the lower interest rates associated with this slowing are likely to lead to better-than-average growth in 1985 and 1986. Moreover, the preponderance of evidence indicates that inflation will not be a problem over the next two years.

These conclusions about the national outlook are based on forecasts generated by a new, highly sophisticated statistical model, known as a Bayesian vector autoregression (BVAR) model. ${ }^{1}$ Developed by research economists at the Federal Reserve Bank of Minneapolis, this model generates forecasts based entirely on its internal structure; that is, no adjustments based on policy assumptions, theoretical considerations, or subjective judgment are involved in the forecasts. (For a general description of the model, see the appendix at the end of this paper.)

The model's point forecasts represent the most likely outcomes for certain economic indicators. But these specific numbers fail to reflect the large degree of uncertainty impossible to eliminate from economic forecasts. One major advantage of our model's statistical approach, however, is that we are able to use it to generate accurate measures of the uncertainties in the forecasts. We can also use the model to measure the probabilities of certain events occurring in the future.

\section{The Forecasts}

The model's 1985 and 1986 point forecasts for selected economic indicators, along with the indicators' average values since World War II, are presented in Table 1 . The forecasts were made using the most recent data available as of November 21, 1984.

\section{Above-Average Growth}

In 1985, according to the model, real growth-measured by the inflation-adjusted gross national product (real GNP) -is most likely to be near 3.7 percent. This forecast contrasts strongly with the rather sluggish growth observed in the second half of 1984 . In addition, this 3.7 percent growth forecast is slightly above the 3.5 percent U.S. postwar average. This strength in 1985 is likely to be broadbased, with especially strong growth in those components of GNP particularly sensitive to interest rates-such as consumer durables, business fixed investment, and residential investment.

The consumer spending component of GNP, constituting roughly two-thirds of total output, is expected to grow at a rate above 4 percent in 1985 and 1986-a rate also above the postwar average of 3.5 percent. The strongest growth in consumption is expected for consumer durables (such as autos and appliances), for which the model predicts an average growth rate of 10 percent in each of the two years.

Investment in business capital as well as in housing is expected to continue at above-average rates over the next two years. The business fixed investment component of GNP is forecast to grow at about 6 percent in 1985 and in 1986-a rate well above the postwar average of 4.7 percent. The housing component of GNP (residential investment) is expected to grow quite strongly in 1985 : after a relatively slow start of about 6 percent in the first

1 For a general description of the methodology used to create BVAR models, see the paper by Todd in this issue. A technical appendix describing this model in detail is available on request to the Research Department, Federal Reserve Bank of Minneapolis. 
Table 1

\section{Point Forecasts for 1985 and 1986 With U.S. Postwar Averages}

\begin{tabular}{|c|c|c|c|c|c|}
\hline \multicolumn{6}{|c|}{ Levels and Growth Rates Over the Year* } \\
\hline Indicator & $\begin{array}{c}15 \\
\text { 4th Qtr. } \\
\text { Level }\end{array}$ & $\begin{array}{l}35 \\
\text { Growth } \\
\text { Rate }\end{array}$ & $\begin{array}{c}15 \\
\text { 4th Qtr. } \\
\text { Level }\end{array}$ & $\begin{array}{l}86 \\
\text { Growth } \\
\text { Rate }\end{array}$ & $\begin{array}{l}\text { U.S. Average } \\
\text { Growth Rate } \\
\text { Since WWII }\end{array}$ \\
\hline Real Gross National Product & $1,703.3$ & $3.7 \%$ & $1,768.9$ & $3.9 \%$ & $3.5 \%$ \\
\hline Consumer Spending & $1,119.4$ & 4.6 & $1,173.9$ & 4.9 & 3.5 \\
\hline Durable Goods & 194.5 & 10.0 & 214.1 & 10.0 & 6.4 \\
\hline Nondurable Goods \& Services & 924.9 & 3.6 & 959.8 & 3.8 & 3.3 \\
\hline Investment & 312.7 & 6.2 & 332.8 & 6.5 & 8.5 \\
\hline Business Fixed & 224.5 & 6.1 & 237.2 & 5.6 & 4.7 \\
\hline Residential & 67.7 & 12.3 & 73.4 & 8.4 & 5.2 \\
\hline Change in Business Inventories & 20.4 & - & 22.2 & - & - \\
\hline Net Exports & -40.5 & - & -54.9 & - & - \\
\hline Government Purchases & 311.8 & 1.4 & 317.1 & 1.7 & 4.3 \\
\hline Civilian Unemployment Rate (\%) & 7.4 & - & 7.2 & - & 5.6 \\
\hline Inflation-GNP Deflator (Index: $1972=100$ ) & 234.0 & 3.2 & 241.6 & 3.3 & 4.1 \\
\hline
\end{tabular}

*Levels are expressed in billions of 1972 dollars, with the exception of the civilian unemployment rate (\% of labor force) and inflation (an index). Growth rates are percentage changes, 4 th quarter over 4 th quarter, but the postwar average for the civilian unemployment rate is a level.

Sources of basic data: U.S. Departments of Commerce and Labor

quarter, housing is predicted to grow at rates in the teens for the rest of the year, resulting in an annual growth rate near 12 percent. In 1986 , housing growth is expected to slow a bit to around 8 percent.

Even though the growth of real GNP is expected to be above average over the next two years (thanks to the strength of the GNP components mentioned above), it will be moderated somewhat by a burgeoning trade deficit, which our model expects will continue to grow. This trade deficit is caused in part by the strong value of the dollar, which has reduced the demand for U.S. exports. The trade deficit shows up as a negative contribution to real GNP in the net exports component. By mid-1986, net exports are expected to reduce real GNP by more than $\$ 50$ billion, or more than double the $\$ 22.7$ billion reduction observed in the third quarter of 1984 . This predicted drop is significant when compared to historical statistics: since World War II, net exports have, on average, contributed \$13.7 billion to GNP, and as recently as the fourth quarter of 1983 , net exports contributed positively to GNP.

The above-average growth expected over the next two years will not have a significant impact on the civilian unemployment rate. The model projects the rate to decline only slowly from its October 1984 level of 7.4 percent and to remain above 7 percent throughout 1985 and 1986.

\section{Optimism About Inflation}

The model is relatively optimistic about inflation in the next two years. Using the GNP price deflator as a measure of inflation, the model projects it to be between 3 and 3.5 percent in both 1985 and 1986 . (The model also predicts that the consumer and wholesale price indexes will both grow at about 3 percent over this period.) The model's optimism seems to run counter to recent precedents, which indicate that inflation tends to rise after the second year of a recovery. For example, during the last two recoveries (not counting the 1980 recovery, which lasted less than two years), the average inflation rate in the third year of recovery was 6.6 percent, up from an average of 4.7 percent in the second year. Even though the current recovery has lasted nearly two years, the model still forecasts low inflation. 


\section{Probabilities and Uncertainties}

As noted above, a considerable degree of uncertainty is always inevitable in economic forecasts. Our model's statistical approach, however, gives us the advantage of being able to generate accurate measures of the uncertainty of its forecasts. And because our model does not require judgmental adjustment of its forecasts, we can confidently use its internal statistical structure to investigate the likelihood of alternative outcomes.

How Likely Is a Recession?

Although the two-year forecast calls for a short pause in real growth followed by continued recovery, we still might want to ask, What is the probability that the current slowdown will deepen and become a recession? To answer this question we must first know what is meant by a recession. Though generally defined as a downturn in economic activity affecting most sectors of the economy, there is no precise definition of recession expressed in terms of real GNP. Nonetheless, all postwar U.S. recessions dated by the National Bureau of Economic Research have shown a drop in the level of real GNP of at least 1 percent. Using this 1 percent drop as our definition, we can calculate the probability of a recession by running the model through 1,000 simulations and measuring the proportion of times the simulated economy meets this criterion. ${ }^{2} \mathrm{We}$ find that between the third quarter of 1984 and the end of 1986 , our model indicates less than a 1-in-6 chance of a drop in real GNP of this size. Moreover, the average postwar U.S. recession has generated a 2.5 percent drop in the level of real GNP. By simulating our model, however, we find that the probability of a decline of 2.5 percent over the next two years is less than 1-in-125.

\section{How Confident Are We About the Forecasts?}

The measures of uncertainty generated by our model allow us to determine how much confidence we can have about our forecasts. The uncertainty of our forecasts can be represented by confidence bands. For example, the shaded portions surrounding the forecasts on Charts 1-3 are confidence bands which indicate a 70 percent likelihood that the actual outcome will fall within the shaded part. Put another way, 30 percent of the time, the actual outcome will not fall within the shaded part: 15 percent of the time it is expected to fall above the band and 15 percent of the time, below. The wider the range indicated by the

2The simulation technique is described in the technical appendix, available on request to the Research Department, Federal Reserve Bank of Minneapolis.
Charts 1-3

\section{Uncertainty in the National Forecasts for Growth, Unemployment, and Inflation}

\author{
1983-3rd Quarter 1984, Actual; \\ 4th Quarter 1984-1986, Forecast \\ With 70 Percent Confidence Bands*
}

Chart 1 Growth (Real GNP)

(Quarterly Percentage Change at Annual Rate)

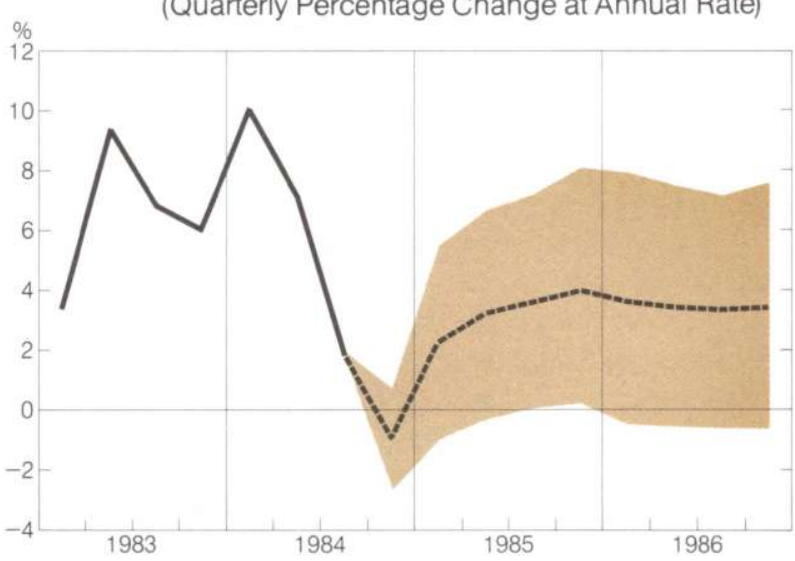

Chart 2 Unemployment Rate

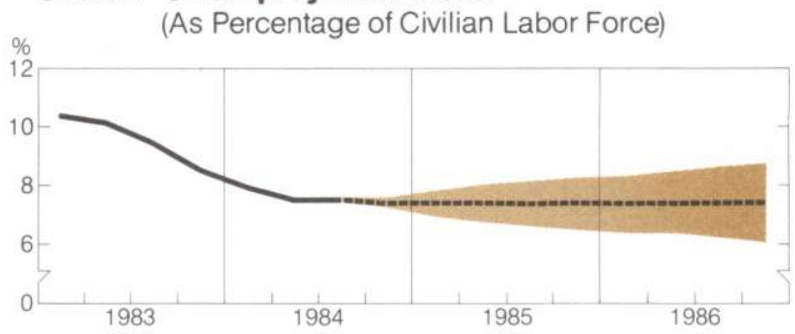

Chart 3 Inflation (GNP Deflator)

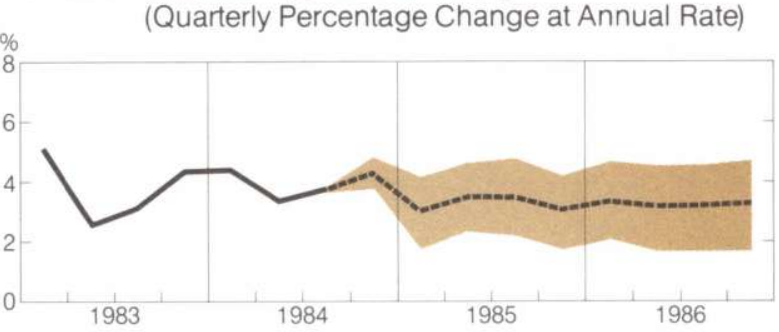

*Most likely forecast surrounded by a range within which the variable is likely to fall 70 percent of the time, based on 1,000 simulations Sources of basic data: U.S. Departments of Commerce and Labor 
band, the less confidence we can have about the forecast; the narrower the band's range, the more confidence we can have.

In Chart 1, the 70 percent confidence band shown around the forecast for real GNP indicates a high degree of uncertainty about real growth in any particular quarter of 1985 and 1986 . The band allows us to see immediately that in any given quarter in the forecast horizon, there is about a 15 percent probability (or a 1 -in- 7 chance) of negative real growth. In fact, we can be relatively confident that in at least one quarter of 1985 or 1986 , GNP will decline. By running simulations on the model, we find the probability of such a one-quarter decline occurring over the next two years is 77 percent, or greater than 3 out of 4 .

The confidence band for the civilian unemployment rate, shown in Chart 2, reveals that it is unlikely for unemployment to fall as low as 6 percent or to rise above 8.5 percent over the next two years.

Through the simulation technique, we find that there is less uncertainty about inflation (measured by the GNP deflator) than about real growth, as shown by the narrower band in Chart 3. Simulations run on the model indicate that in any given quarter during the next two years, there is a greater than 1 -in- 2 chance of inflation being between 2 and 4 percent and a less than 1 -in- 16 chance of inflation being above 5 percent.

\section{Summary}

Despite the slowdown in economic growth during the second half of 1984, the BVAR model forecasts at least two more years of above-average growth for the U.S. economy. Although there is considerable uncertainty with this forecast, as there is with any economic forecast, the model suggests only a small probability of recession and very little likelihood of a significant increase in inflation for 1985 and 1986.

\section{Appendix Modeling the National Economy}

Our Bayesian vector autoregression (BVAR) model of the national economy is designed to forecast at short and long time horizons as accurately as possible. In order to capture the current economic outlook as quickly and clearly as possible, we use monthly data in the model. To forecast accurately at horizons a year or more ahead, we include more than a year's worth of lagged values for each variable in each of the model's equations.

The model is designed to incorporate a good deal of detail about the various components of real GNP; at the same time, it has been kept to a manageable size so that estimation, forecasting, and simulation do not become too time-consuming and expensive. The 46 equations included in the model represent the compromise required to meet the competing objectives of sufficient detail and manageability.

\section{The Basic Structure}

The main interactions in the model (shown in the diagram) are generated in a core sector that includes eight variables: real GNP, the GNP deflator, the 3-month Treasury bill rate, the Standard \& Poor's 500 stock-price index, the money supply (M1), the value of the trade-weighted dollar, total nonfinancial debt, and the change in business inventories. Along with the core sector, there are seven other sectors that respectively model production, labor, financial markets, consumption, government, international trade, and prices. The variables in the core sector feed into the other sectors, whose variables in turn feed into others. (A technical appendix describing the model's structure in detail is available on request to the Research Department, Federal Reserve Bank of Minneapolis.)

\section{Preparing the Data}

In order to implement the model, two special problems in preparing the data must be solved. (These problems and their solutions are also detailed in the technical appendix.) The first problem involves constructing a monthly data base. Since many of the most important variables, such as real GNP and the GNP deflator, are only published as quarterly data, we must derive their monthly versions. To do this we take each component of the variable and use related monthly series to estimate the underlying monthly values for that component. All told, we use data from 81 different series to estimate values for variables in the model's 46 equations. The second problem in preparing the data is that many of the series we use are not published in seasonally-adjusted form. In these cases, we seasonally adjust the data. 


\section{The Main Interactions of Our Model's Variables}

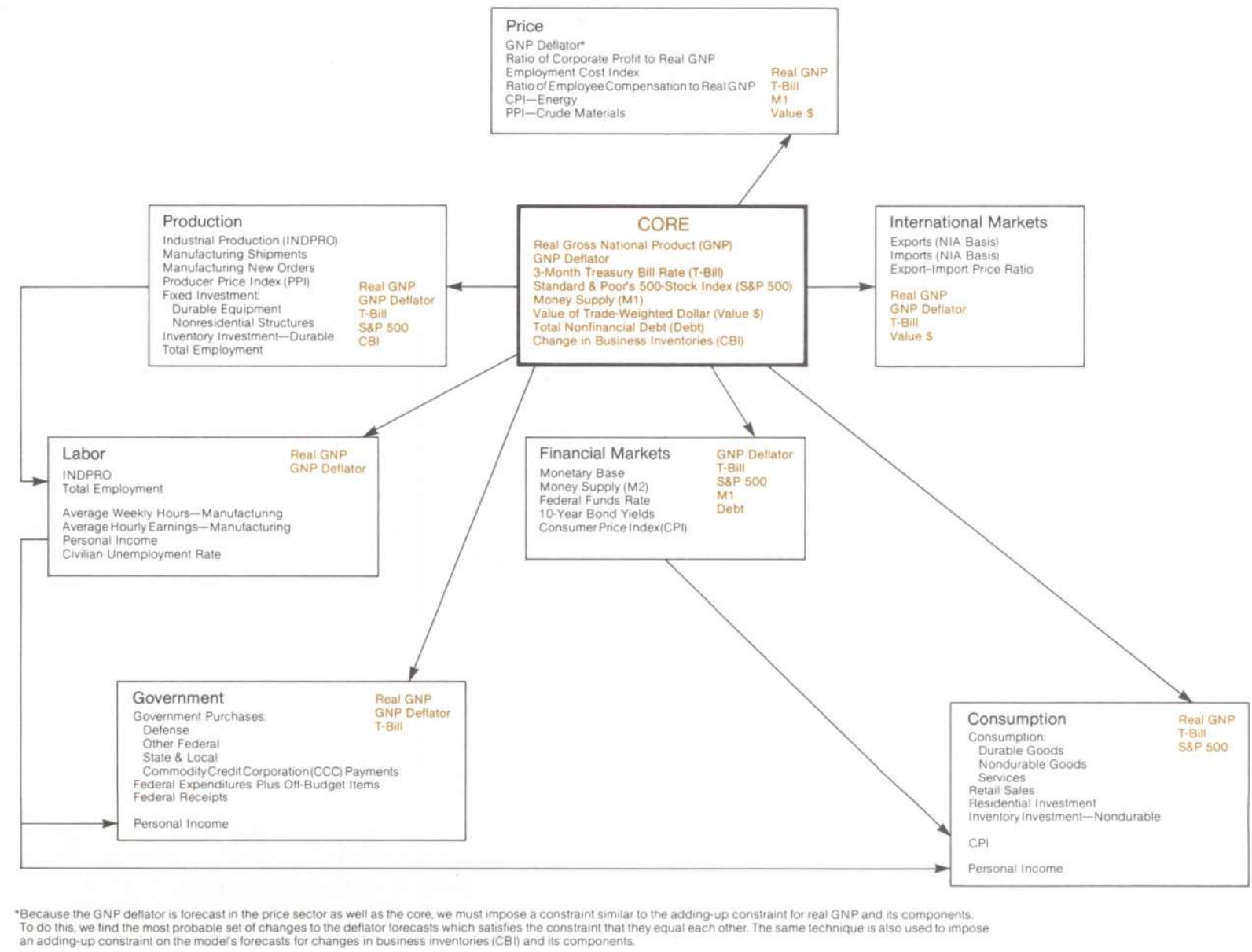

\section{Generating Forecasts and Measuring Uncertainty} After solving the problems involved in preparing our current data set, we estimate the equations in the model. We then generate an unconditional (baseline) forecast-a forecast that doesn't require special assumptions about policy or other conditions. We simply assume that all variables in the model, including policy-related ones (such as interest rates and the money supply), will behave in the future as they have in the past. For each month in the forecast horizon, we must impose several "adding up" constraints. For example, the sum of the components of real GNP from the various sectors must add up to the real GNP forecast from the core sector, so we find the most probable set of changes to the components and the total that satisfies the constraint. We can also use the model to generate conditional forecasts-forecasts that predict what might happen if a given condition exists. (For further discussion of the uses of BVAR models in conditional forecasting, see the Litterman paper on forecasting and policy analysis in this issue.)

To measure the uncertainty involved in the forecasts-either conditional or unconditional-we can run simulations on the model. Using these simulations we can generate confidence bands and calculate the probabilities of future events. The model's simulation program is by far the most expensive computational step: 1,000 simulations take about three hours of computer time to run. 